\title{
A practical approach to development of housing on floodplain land in the UK
}

Received (in revised form): $27^{\text {th }}$ January 2009

\author{
Simon Mclean \\ is Senior Lecturer in Building Surveying at Sheffield Hallam University, UK. Simon is a Chartered Building Surveyor \\ practicing in the United Kingdom. He teaches practical Building Surveying at Sheffield Hallam University. Being \\ located professionally in South Yorkshire and the East Midlands he viewed the events of 2006-2007 when large \\ areas of Sheffield, Rotherham, Humberside and Nottinghamshire were subject to severe flooding.
}

\section{Paul Watson}

is Professor of Building Engineering and Head of Construction, Cost and Surveying at Sheffield Hallam University. Paul's experience is varied, having spent some years in the construction industry as a project manager where he gained practical knowledge before entering the world of academia. Paul has not lost his industrial roots and he has written numerous publications on construction and surveying-related topics including authoring and co-authoring eight text books that have practical application. He has also designed degree courses that specifically address the requirements of building engineers and surveyors.

Correspondence: Simon Mclean, Sheffield Hallam University, 40 Milton Drive, Ravenshead, Nottinghamshire NG15 9BE, UK

ABSTRACT Recent flooding in the United Kingdom has resulted in a backlash against building activities taking place on floodplains, with further concerns being expressed that insurers may withhold flood damage cover from properties in areas which carry a flood risk. Given the high demand for new homes and a lack of alternative building land, a prohibition of building on floodplain land is unsustainable. The authors propose a proactive regime of site investigation, risk analysis and risk management before developing floodplain sites. This regime will comply with government guidelines published in PPS25, which deals with 'Development and Flood Risk'. It is accepted that perceived risk levels on certain sites may be deemed too high, even after proactive management action has been deployed to appease the insurers. The authors seek to consider alternative property designs, which can accommodate rising flood waters and reduce damage costs to minimal acceptable levels, in all but the most extreme of flood conditions. The paper contains examples and evaluation of flood-resistant technology; this is undertaken in order to establish whether an alternative strategy to the abandonment of development proposals is a practical viable proposition within the United Kingdom.

Journal of Building Appraisal (2009) 4, 311-320. doi:10.1057/jba.2009.10

Keywords: flooding; floodplain; flood resiliance; flood remediation; flood insurance; flood resistance

\section{INTRODUCTION}

Since the turn of the millennium, when in the year 2000 the United Kingdom experienced the wettest autumn on record which resulted in 10000 flooded homes, the possibility of further flooding has been an important consideration. In subsequent years there have been a number of high profile floods, with large numbers of homes in Carlisle, Tewksbury, Glasgow, Sheffield and Hull being under water, and homes in many other parts of the 
United Kingdom similarly affected. Predictions are that winters will become milder and wetter and sea levels shall rise, resulting in an increased risk of flooding in the United Kingdom (PPS25, 2006). According to the Concrete Centre, over half a million homes were at risk of flooding in 2007, and due to climate changes the figure is set to rise further (Concrete Centre, 2007). They additionally cite figures from the Association of British Insurers (ABI) of typical flood remediation costs of $£ 20.9$ million per year and average individual claims being $£ 22000$ for buildings and $£ 13000$ for contents (Concrete Centre, 2007).

\section{BUILDING ON FLOODPLAINS}

Perhaps unsurprisingly the level of flooding now experienced by the United Kingdom has led to an adverse reaction against development taking place on floodplains. Headlines such as 'Fears over plans for new homes in Tewkesbury floodplain' (Western Daily Press, 2008), and 'Victims march against building on floodplains' (Smith, 2007) became commonplace. However, the government has clearly become cognisant of the fact that there is a finite amount of appropriate building land available. This is due to the United Kingdom's island state, the sheer volume of floodplain land created by the climate and topography of the United Kingdom and demand for 00000s of new homes. Thus there is an inadequate amount of non-floodplain or brown field land available to meet the United Kingdom's high demand. Therefore in the face of public demand for housing the government and hence the planning authorities have continued to allow development to take place on floodplain areas.

\section{FLOOD DAMAGE TO DWELLINGS}

As stated, a typical insurance claim for the flooding of a property would be $£ 35000$, of which $£ 13000$ relates to contents damage. Therefore the removal of contents from flood damage would reduce claim values by over a third, and in fact it is the porous, plaster, timber, decorative materials and services located within the living accommodation which suffer greatest degradation when saturated (see Figures 1 and 2). Another high value cost of flooding events is that of structural damage caused when the flow of floodwaters is checked and contained within the structure. The forces this releases can cause structural damage to both substructure and superstructure elements (Kenna, 2008). Ensuring that floodwaters have unhindered passage through a property could ensure significant reductions in repair costs. A previously unattributed cost associated with flooding activities is that of the displacement of occupants, which usually forms part of an insurance claim. It is estimated that 3000 victims of the 2007 flooding in Humberside were still living in temporary accommodation a year after the event (Kenna, 2008).

\section{FLOOD INSURANCE}

Pivotal to the resale value of a domestic property is the ability of the purchaser to protect their investment against losses, which in the current climate would clearly include the flooding of their property. However in the light of their perception that the government has failed to allocate sufficient funds for flood defences, the ABI are set to reconsider their position regarding continued cover against flood damage for properties built in high risk areas (Francis, 2007). An article in the Times newspaper by Clare Francis reported on the impact of such an action on house values and cited a drop in value up to 80 per cent (Francis, 2008). The report further quotes the RICS as saying a failure to obtain adequate insurance would prevent mortgagers from lending on such property 


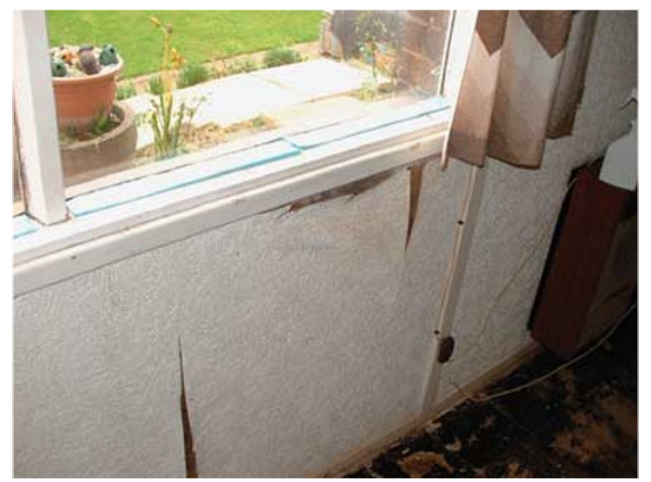

Figure I: Damage to decor is clear; however, damage to timber elements such as the frame of the window and flooring is also apparent. Low level services are subject to flood damage risk.

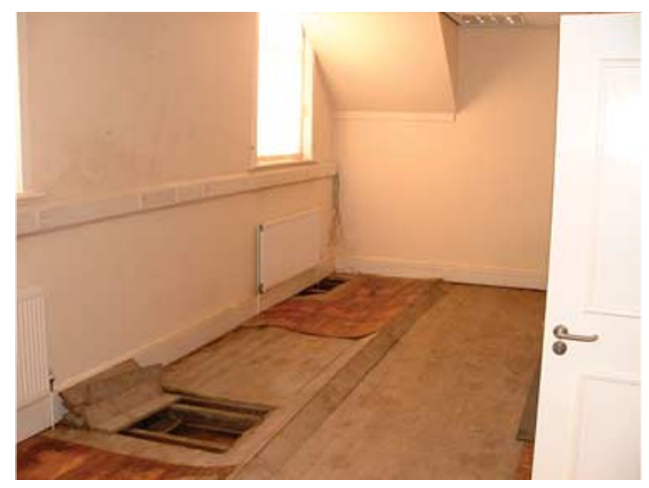

Figure 2: While high level services appear to be a flood-resilient measure, use of timber flooring materials has resulted in structural damage.

and also render them unsaleable (Francis, 2007). In an economic climate which has already experienced a doubling of home insurance premiums for similar properties in the previously flooded Tewkesbury over nearby Stroud (Francis, 2007), this factor more than planning restriction is likely to limit the construction of houses which are susceptible to flood damage.

\section{PLANNING POLICY AND CONSTRUCTION GUIDANCE}

Planning Guidance Statement number 25 appertains to development and flood risk and was first published in December 2006 (HMG, 2006). As such it provides the most current guidance available for planning authorities considering planning applications to develop floodplain land. It advocates a three-phased approach for future development. First, it suggests a thorough Appraisal of the Risk. This involves the identification of land which is at risk of flooding and the determination of the degree to which that risk extends. The evaluation is to be undertaken through the production of Regional Flood Risk Appraisals. It would appear that the insurance industry is already equally active in producing such appraisals for its members use (Francis, 2007). Figure 3 provides a flow diagram of the appraisal process. This flow diagram has been developed for this paper by the authors in order to try and make the process more readily understandable for all concerned with the planning application and evaluation activities. 


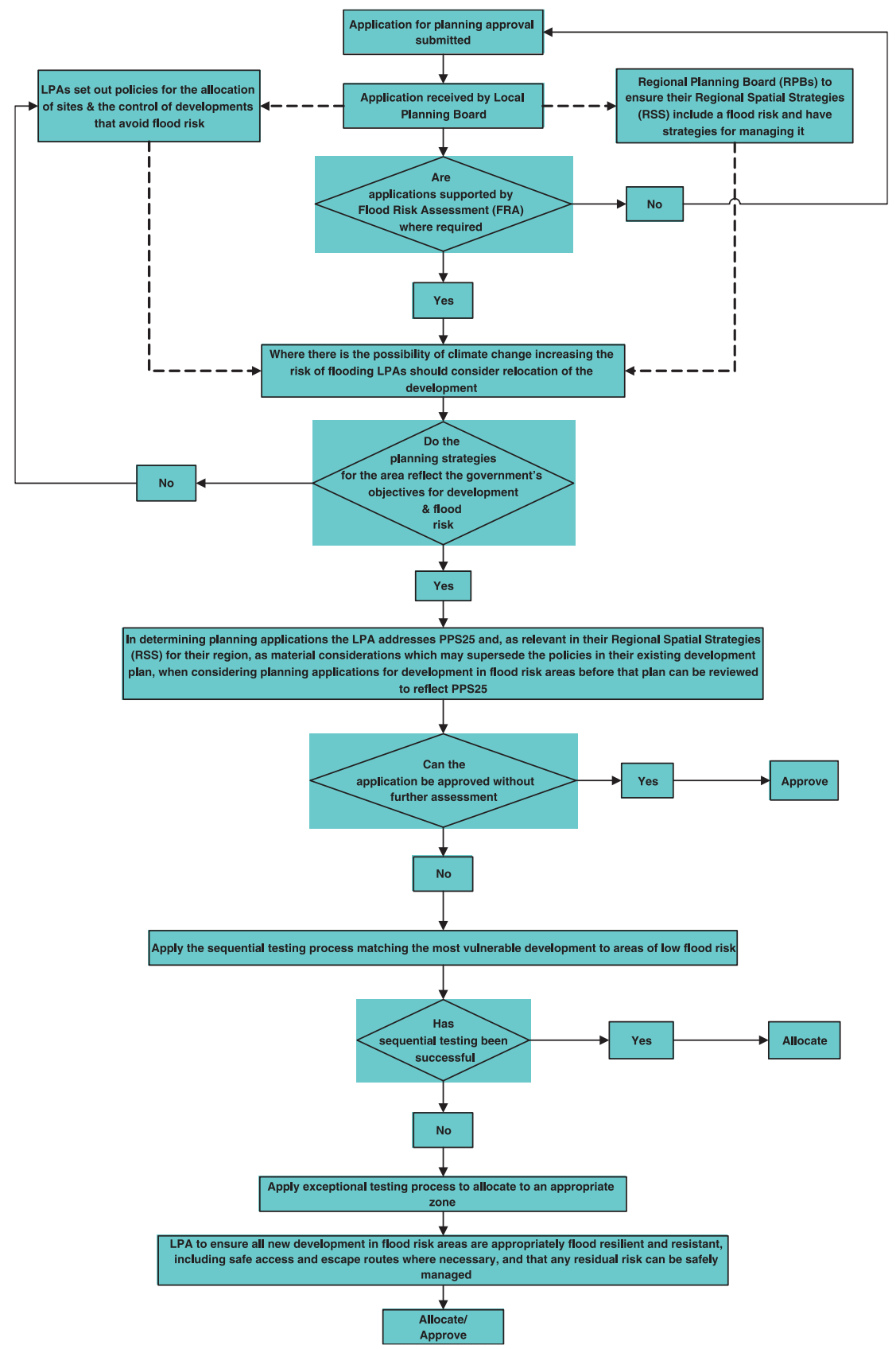

Figure 3: Flood risk assessment process.

The second phase is the Management of Flooding Risk, and this is cited as being measures designed to avoid the risk of flood damage occurring wherever possible, through proactive management of flood defences, and sustainable drainage systems. PPS25 carries the caveat that development of floodplain land must only take place where the benefits of development outweigh the risk of flooding. Finally, PPS25 advocates a Reduction of Risk through conservation of land required for flood management, implementation of sustainable drainage and flood defences and through the location, layout and design of new developments. 


\section{SYSTEM FOR OBTAINING PLANNING APPROVAL TO DEVELOP FLOODPLAIN LAND}

Figure 3 utilises PPS25 and describes a process which should be undertaken when seeking planning approval to develop potential floodplain land. Clearly the process includes an assessment regime which establishes whether the risk of flooding can be managed within current government strategies. Further, it embraces the establishment of plans for the management of flood risks; however, without an adequate investment in the funding for flood defences to remove any flood risks or another guarantee of reduction in the potential property damage caused by flooding, even though planning approval is granted the insurance companies may still refuse to offer flood insurance or increase premiums to unsustainable levels.

\section{PROPOSALS FOR A TWO-PHASED STRATEGIC APPROACH IN THE SUCCESSFUL DEVELOPMENT OF FLOODPLAIN LAND}

The authors accept that in spite of a knee-jerk reaction against the development of floodplain land by those affected by recent floods, if targets for new dwellings are to be met such development must continue. However, there is a significant risk that British Insurers will refuse to provide flood insurance for properties in locations where there is a higher risk of flooding, hence rendering these properties unsaleable. The only solution would be to adopt a two-phased approach when developing floodplain land.

The first phase is the adoption of a further regime of appraisal and risk management in line with PPS25, undertaken in order to identify, quantify, manage and reduce the risk of flooding to acceptable levels for the ABI. To this end the authors have proposed a model in the form of a flow diagram which is depicted in Figure 4 and is related to risk assessment. The second is to evaluate current property designs which are flood resistant, and further to investigate if such designs, which are currently available could prove to be sustainable within the United Kingdom. As it is the authors view that the alternative of using an Asian model of houses built upon stilts would be unlikely to find a serious market in the United Kingdom. By successful adoption of this approach the aims of neutralising the additional flooding risks caused by climate change, and of protecting the property and contents from expensive flood damage can be mainly achieved.

\section{RISK ASSESSMENT AND MANAGEMENT PLAN FOR POTENTIAL FLOODPLAIN SITES}

As noted Figure 4 provides a pictorial representation of a risk assessment process. The noted process has been designed by the paper's authors in order to aid the risk assessment related to possible Flood Damage. The first set of activities identified on the flow diagram are those associated with any project, that is the determination of project aims and the establishment of the required resources for successful completion (attainment of aims). However, the flow diagram also incorporates a Flood Risk Analysis activity. The noted risk assessment activity is based on the Likelihoood Impact Scoring Technique (LIST), and Table 1 provides the criteria to be applied when applying the LIST analysis. It can be seen that the application of a LIST assessment requires the determination of the likelihood of the event occurring along with a further evaluation of its impact. The result of establishing these two factors is the calculation of a numerical score, which provides quantitative data to be incorporated into the decision-making process. 


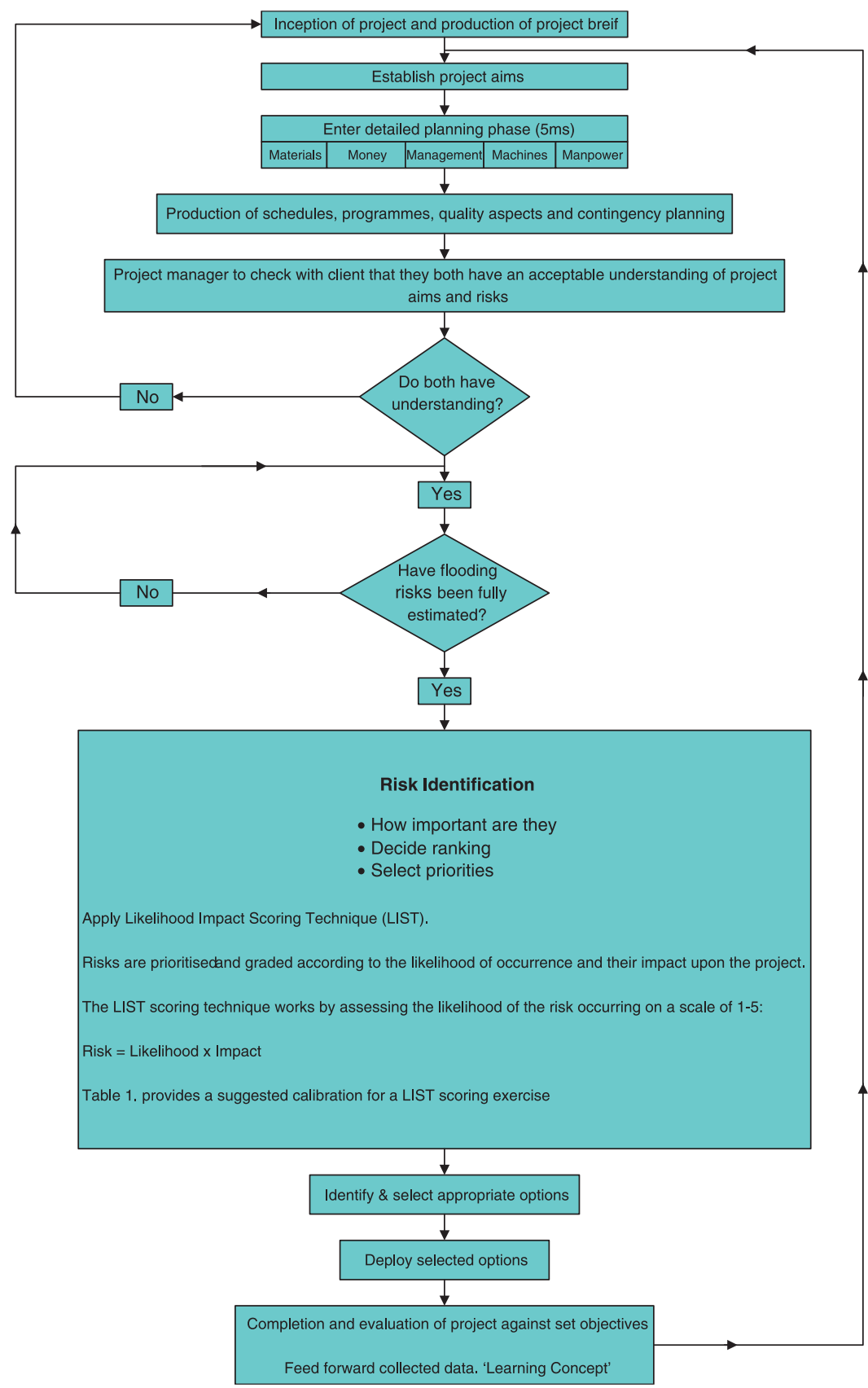

Figure 4: Project flood risk assessment.

For example, the LIST scoring technique works by assessing the likelihood of the risk occurring on a scale of 1-5 and its impact on the project should it occur.

Therefore, Risk $=$ Likelihood of Occurrence $\times$ Impact of Risk example:

Likelihood of Risk $5 \times$ impact (marginal) value of $2=$ value of 10 LIST Factor 
Table I: LIST scoring criteria

\begin{tabular}{lll}
\hline Score & Likelihood of risk & Impact of risk \\
\hline 5 & Over $90 \%$ & Catastrophic \\
& Highly probable & Critical \\
4 & $70-90 \%$ & Serious \\
3 & Very likely & Marginal \\
2 & Over $30 \%$, Less than 705 & Insignificant \\
& As likely as not & Could happen \\
\hline
\end{tabular}

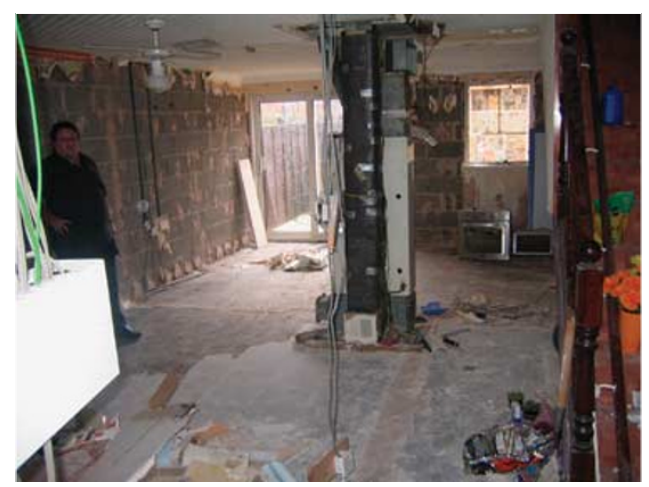

Figure 5: Flood damage has resulted in the total demise of all internal decorative plasterwork, internal partitions and floor coverings. Concrete- and UPVC-based elements remain undamaged.

The provision of the quantitative data as part of a decision-making process can improve the quality of decisions taken in relation to managing Flood Risk. The LIST technique responses can involve one or a combination of the following:

- Removal - risk eliminated from the project;

- Reduce - taking actions before possible occurrence that reduce the associated risk;

- Avoid - taking contingency actions can mitigate risks or making contingency allowances in the event they occur;

- Acceptance - the benefits achieved by taking the risk must at least balance against resulting penalties;

- Transfer - if possible move the risk element, probably by insurance transfer.

The final aspect of the flow diagram addresses the critical issue of 'Learning from the Experience'. This means conducting an evaluation of the results obtained, did the action work and if not why not? This process is based on the common activity of providing feedback; however, learning and improving is based on converting feedback into feed forward information. This activity is undertaken to ensure that any mistakes are not repeated, and hence improvements can be made on future projects.

Having a scored assessment of flood risk, of a type that the insurance industry uses to assess underwriting risks will allow the development team to provide even more proactive technical solutions to mitigating flood risks where it is deemed required to appease underwriters. 


\section{FLOOD-RESISTANT AND FLOOD-PROOF CONSTRUCTION}

Materials such as concrete and masonry are more flood resilient than other building materials as they do not warp, decay or lose structural integrity as a result of flooding (Concrete Centre, 2007) (see Figure 5). However the concrete centre's own figures purport that a large proportion of flooding restitution costs are associated with house contents, and internal finishes, which are not suitable for manufacture from concrete-based materials. Ensuring that any part of a structure exposed to flooding is made from concrete or masonry is a fine aim, but not practical. This means that the only sustainable way of reducing remedial costs from water entering living accommodation is to keep such accommodation out of harm's way. Two forms of building design have already been developed to achieve this. The first locates garaging and storage areas on the ground floor, elevating living accommodation to the upper storeys. The second developed in the Netherlands utilises a concrete raft foundation which floats upwards on retaining columns as floodwaters approach and then settles back in position when they recede. Each form can utilise an architectural form that does not clash with the traditional UK house form, as in non-flood conditions each appears to be what has become to be accepted as a traditional house style. It is also worth noting that 'The most important measure that can be taken to reduce the impact of flooding is to raise the minimum floor level of the property above expected flood levels' (Office of Deputy Prime Minister, 2003).

The Department of Civil Engineers at the University of Bristol investigated a number of options for providing a flood proof house (Han et al, 2002). Many sought to exclude water by creating a watertight seal around the property, which is an approach not without risk of water breach. There may also be subsequent ponding of the water and associated possible structural damage after the flood waters have subsided. Also included was the wet floodproofing model. This allowed floodwaters to pass through uninhabited parts of the building in a controlled manner. The requirement for this method is for hydrostatic pressures to be equalised when the ground floor area is flooding, to remove the possibility of damaging the building's structural foundation. This means that the design must allow the floodwaters to pass through the house and not dam in any area. Additionally the area to be flooded must be fully resistant to flood waters especially drainage and electrical control systems, which need to be located above the water level. The area would be constructed using in situ concrete, pre-cast concrete and concrete blocks as these will not suffer water degradation.

The report does however conclude that barring a super flood with waters rising over the height of the first storey, the design should require only minimal remedial works following a severe flood (Han et al, 2002). An example of such a constructed house within the United Kingdom is that of a conversion of a mill in Angus which was designed by Walker Architects and located in the North Esk floodplain. The entire ground floor is set aside as a utility and children's play area, whereas the main entrance to the property has been relocated by staircase to the first floor. The loss of living accommodation has been replaced by the insertion of a timber third storey which was built off site and craned into position. The property which was previously uninhabitable now provides excellent domestic accommodation (Walker, 2008).

Such a form of construction may find greater use as one of the powers given to planning authorities in flood risk areas is to specify a minimum ground floor level as a condition of providing planning permission (Office of Deputy Prime Minister, 2003). However, the additional height of such buildings is seen as a possible obtrusion in certain landscape situations (Office of Deputy Prime Minister, 2003). In such a situation the use of artificially raised ground could be advocated in lieu of a service storey. This effectively renders the house to be a traditional two storey property, rather than a three storey one. 
This option was investigated by civil engineers at the University of Bristol, but concerns over possible landslides in flood conditions were noted (Han et al, 2002).

Another possible solution which adopts the traditional two storey form is the floating house. This design is based around a hollow concrete raft foundation devised so that the basement can be used for storage, and the house which is built to a lightweight design sits on the raft. The whole structure is connected to its site by vertical columns located from piled pads. These allow the house to move in the vertical plain while preventing any other form of movement. When the flood waters arrive, the house rises with the water, floating upon its hollow raft, and settles back in to position as the waters ebb away.

There are a number of design problems to overcome with this form of construction, because most of the raft would remain submerged and hence the concrete raft has to be of adequate depth, watertight and structurally resistant against the pressures exerted by flood waters. The locating columns must be both tight and sturdy to prevent any lateral movement, but also durable and flexible enough to resist excessive deformation and possible fracture. Finally the raft must be anchored to prevent any groundwater movement in non-flood conditions (Han et al, 2002). An alternative to the concrete raft was cited by Bristol University as being a wider structure made from lighter materials; however, the authors believe that such a move would result in the perception of the property being taken away from a technically advanced house to one of being a landlocked house boat.

The concept of such flood secure homes is a reality. In the Netherlands a country with more than most to fear from rising sea levels large numbers of these houses have been built. In Maasbommel on the floodplain of the river Maas, a number of such houses can achieve a rise of $4 \mathrm{~m}$ in response to flooding. Built in response to a lack of non-flood risk land in this popular area, the houses sit on a hollow concrete cube, and utilise flexible service piping. At a price of $£ 180000$ they are more expensive than traditional builds, but this may be balanced in the future by the cost differential of land rendered redundant for the purposes of using traditional construction methods. Clad in yellow, green and blue panels the Dutch houses might fall outside of the traditional British idea of a home; however, utilisation of a more vernacular architectural form would not detract from the true function of the house. The houses are reputedly popular with Dutch buyers (BBC News, 2007).

The concept of the rising house is not purely a UK civil engineering department exercise. Alison Brooks Architects designed Salt House which was built on the Blackwater Estuary in Essex and uses a system of mini-piles and jacks to hydraulically lift the house out of harms way in extreme conditions. Although not strictly a floating house, as it effectively becomes a house on stilts when jacked up, and allows the floodwaters to flow through, rather than lift the structure, it does corroborate the feasibility of building such flood avoidance houses in the United Kingdom (e-architect, 2007).

A recent proposal for building hundreds of floating homes on the docklands in the river Ribble floodplain at Preston in Lancashire received a reportedly enthusiastic welcome from the local authority. The structures apparently utilising the Dutch design would allow development of this flood-prone area; however, opposition to the scheme centres on the removal of an operational floodplain for surrounding areas (Lancashire Evening Post, 2007), which evidences the need for the prior risk assessment and management strategy advocated by PPS25.

\section{CONCLUSIONS}

Demand for additional housing in the United Kingdom, coupled with a shortage of suitable available land means that prohibiting the development of potential floodplain land is not a viable strategy. Numerous high profile and costly flooding events 
experienced over the last decade have resulted in pressure being put on the insurance industry. This pressure is in respect of continuing to provide cover at a competitive acceptable cost for dwellings built on floodplain land. The government have produced a guidance methodology for the assessment of flood risks, and further guidance in respect of providing flood resistance and reliance, should a site suffer from flooding. This paper proposes a methodology for the assessment of flood risk based upon the government's guideline document Planning Policy Statement Number 25, Development and Flood Risk, and further more proactive assessment of flood probability. However the authors accept that should the assessment deem a level of flood risk which is unacceptable to insurers when related to traditionally constructed dwellings, then developers might need to consider less traditional, but ultimately more flood-resistant technologies in order to reduce the potential insurance claim costs in the event of flooding taking place. The authors were able to investigate two types of construction form which are currently practically employed in high flood risk areas, but which are significantly different to the normal construction form used in the United Kingdom. However this need not be significantly so, given that they could be more widely adopted. The advantage of their deployment is that in the event of any but the most extreme of flooding circumstances the damage to the property would be minimal, consequentially they could be offered insurance.

By conducting a stringent site assessment to establish existing levels of risk, and where required, practical and proactive property design being undertaken, then the essential development of available building land could be continued. This should also result in the owners of such property being able to obtain a mortgage and adequate insurance cover.

\section{ACKNOWLEDGEMENTS}

Photographs were taken by Samuel Astbury who is a Building Surveyor and who was employed in flood damage remediation in the aftermath of the Humberside floods of 2007.

\section{REFERENCES}

BBC News. (2007) Dutch pioneer floating eco-homes, www.news.bbc.co.uk, accessed 1 March 2007.

Concrete Centre. (2007) Concrete Reduction in Flood Damage, Technical Note TCC300, released 14 March 2007

London: The Concrete Centre.

Francis, C. (2007) Flood homes: Prices could fall 80\%. Timesonline, 26 July, www.timesonline.co.uk.

e-architect. (2007) Essex House by Alison Brooks Architects England, UK, www. Guardian.co.uk.

Han, D., Davis, J., Hu, Z., Lan, G., Maren, E. and Twyman, C. (2002) Design Studies on Flood-Proof House. University of Bristol Academic Report Sponsored by ICE R\&D Enabling Fund, Bristol.

HMG. (2006) Planning Policy Statement 25: Development and Flood Risk. London: The Stationery Office.

Kenna, S. (2008) Do social housing providers across Yorkshire and the East Midlands have effective flood risk management in place when maintaining and repairing their housing stock? Journal of Building Appraisal 4(2): 71-85.

Lancashire Evening Post. (2007) Floating homes plan for Preston. 28 August, www.lep.co.uk.

Office of Deputy Prime Minister. (2003) Preparing for FLOODS. Wetherby, UK: ODPM Publications (PC 01CD1025).

Smith, D. (2007) Victims march against building on flood plains. The Observer, 19 August, London.

Walker, M. (2008) Houses, Logiemill, Angus, www.walkerarchitecture.co.uk.

Western Daily Press. (2008) Fears over plans for new homes in Tewkesbury floodplain. Friday, 25 July, www.

westerndailypress.co.uk. 